\title{
Effects of growth hormone on cardiac remodeling and soleus muscle in rats with aortic stenosis-induced heart failure
}

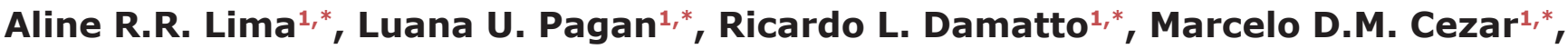 \\ Camila Bonomo ${ }^{1, *}$, Mariana J. Gomes ${ }^{1, *}$, Paula F. Martinez ${ }^{2, *}$, Daniele M. Guizoni ${ }^{1, *}$, \\ Dijon H.S. Campos ${ }^{1, *}$, Felipe C. Damatto ${ }^{1, *}$, Katashi Okoshi, ${ }^{1, *}$ and Marina P. Okoshi, ${ }^{1, *}$ \\ ${ }^{1}$ Botucatu Medical School, Internal Medicine Departament, Sao Paulo State University, UNESP, Botucatu, Brazil \\ ${ }^{2}$ School of Physical Therapy, Federal University of Mato Grosso do Sul, Campo Grande, Brazil \\ *These authors take responsibility for all aspects of the reliability and freedom from bias of the data presented and their \\ discussed interpretation
}

Correspondence to: Marina P. Okoshi, email: mpoliti@fmb.unesp.br

Keywords: heart failure, skeletal muscle, growth hormone, muscle trophicity, satellite cells

Received: March 28, $2017 \quad$ Accepted: July 29, $2017 \quad$ Published: August 24, 2017

Copyright: Lima et al. This is an open-access article distributed under the terms of the Creative Commons Attribution License 3.0 (CC BY 3.0), which permits unrestricted use, distribution, and reproduction in any medium, provided the original author and source are credited.

\section{ABSTRACT}

Background: Skeletal muscle wasting is often observed in heart failure (HF). The growth hormone (GH)/insulin-like growth factor-1 (IGF-1) axis is impaired in HF. In this study, we evaluated the effects of $\mathrm{GH}$ on soleus muscle and cardiac remodeling in rats with aortic stenosis (AS)-induced HF.

Methods: AS was created by placing a stainless-steel clip on the ascending aorta. After clinically detecting HF, GH ( $2 \mathrm{mg} / \mathrm{kg} /$ day) was subcutaneously injected for 14 days (AS-GH group). Results were compared with those from Sham and non-treated AS groups. Transthoracic echocardiogram was performed before and after treatment. Protein expression was evaluated by Western blot and satellite cells activation by immunofluorescence. Statistical analyzes: ANOVA and Tukey or Kruskal-Wallis and Student-Newman-Keuls.

Results: Before treatment both AS groups presented a similar degree of cardiac injury. GH prevented body weight loss and attenuated systolic dysfunction. Soleus cross-sectional fiber areas were lower in both AS groups than Sham (Sham

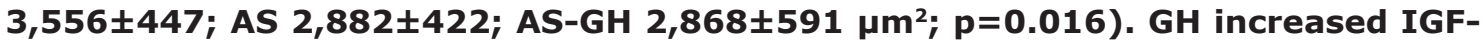
1 serum concentration (Sham 938 \pm 83 ; AS 866 \pm 116 ; AS-GH 1167 $\pm 166 \mathrm{ng} / \mathrm{mL}$; $\mathrm{p}<0.0001$ ) and IGF-1 muscle protein expression and activated PI3K protein. Neural cell adhesion molecule (NCAM) immunofluorescence was increased in both AS groups. Catabolism-related intracellular pathways did not differ between groups.

Conclusion: Short-term growth hormone attenuates left ventricular systolic dysfunction in rats with aortic stenosis-induced HF. Despite preserving body weight, increasing serum and muscular IGF-1 levels, and stimulating PI3K muscle expression, GH does not modulate soleus muscle trophism, satellite cells activation or intracellular pathways associated with muscle catabolism.

\section{INTRODUCTION}

A major symptom in patients with chronic heart failure is a reduced tolerance to exercise caused by the early occurrence of dyspnea and fatigue. In addition to impaired ventricular function, noncardiac factors contribute to exercise intolerance. Metabolic, molecular, and functional skeletal muscle abnormalities have often been observed and are considered to play an important role in the symptoms [1]. Muscle wasting is a common disorder which often precedes cachexia and predicts frailty, poor quality of life, and mortality in heart failure [2,3]. Despite 
Table 1: Anatomical data

\begin{tabular}{|c|c|c|c|}
\hline Variables & $\begin{array}{l}\text { Sham } \\
(n=17)\end{array}$ & $\begin{array}{c}\text { AS } \\
(n=13)\end{array}$ & $\begin{array}{c}\text { AS-GH } \\
(n=10)\end{array}$ \\
\hline BW (g) & $484 \pm 42$ & $415 \pm 31^{*}$ & $476 \pm 58 \#$ \\
\hline LV (g) & $0.84 \pm 0.12$ & $1.22 \pm 0.26^{*}$ & $1.42 \pm 0.24^{*}$ \\
\hline RV (g) & $0.29 \pm 0.06$ & $0.50 \pm 0.09 *$ & $0.60 \pm 0.10^{*} \#$ \\
\hline Atria (g) & $0.09 \pm 0.02$ & $0.33 \pm 0.10^{*}$ & $0.39 \pm 0.06^{*}$ \\
\hline Soleus (g) & $0.23 \pm 0.03$ & $0.19 \pm 0.02 *$ & $0.21 \pm 0.04$ \\
\hline LV/BW (mg/g) & $1.73 \pm 0.17$ & $2.93 \pm 0.57 *$ & $2.91 \pm 0.46^{*}$ \\
\hline RV/BW (mg/g) & $0.61 \pm 0.13$ & $1.20 \pm 0.22 *$ & $1.23 \pm 0.19^{*}$ \\
\hline Atria/BW (mg/g) & $0.20 \pm 0.03$ & $0.80 \pm 0.23^{*}$ & $0.79 \pm 0.11 *$ \\
\hline Lung (g) & $2.17 \pm 0.50$ & $3.52 \pm 0.76^{*}$ & $3.94 \pm 1.18 *$ \\
\hline Lung/BW (mg/g) & $4.53 \pm 1.25$ & $8.53 \pm 1.96^{*}$ & $8.12 \pm 2.74^{*}$ \\
\hline
\end{tabular}

Data are expressed as mean \pm standard deviation. AS: aortic stenosis; AS-GH: aortic stenosis treated with growth hormone; n: number of animals; BW: body weight; LV: left ventricle; RV: right ventricle. ANOVA and Tukey; ${ }^{*}$ p $<0.05$ vs Sham; \# $\mathrm{p}<0.05$ vs AS.

being clinically important, its pathophysiology is not completely understood and a therapeutic approach for preventing muscle wasting and recovering muscle mass has not been established [3].

Growth hormone $(\mathrm{GH})$ is essential for metabolic homeostasis and muscle growth and function [4]. GH exerts its effects either by direct action or mediated by the insulin-like growth factor-1 (IGF-1) [5, 6]. The GH/IGF-1 axis can suppress protein breakdown and stimulate skeletal muscle hypertrophy by inducing myocyte survival, differentiation, and proliferation [7-10]. However, the mechanisms involved in $\mathrm{GH}$-induced mass preservation in pathologic conditions are not completely understood. IGF-1 can modulate muscle trophism by stimulating proliferation and differentiation of satellite cells, which are mononuclear and undifferentiated cells located between muscle fiber basal lamina and sarcolemma [11, 12]. At basal conditions, these cells remain in quiescent state; after harmful stimuli to the muscle, they are activated and named myogenic precursor cells or myoblasts $[13,14]$.

Clinical studies have shown that the GH/IGF-1 axis is impaired in heart failure with approximately $40 \%$ of patients presenting GH or IGF-1 deficiency [15-20]. IGF-1 is mainly reduced in patients with severe heart failure [21] or cardiac cachexia [17]. Low IGF-1 levels are associated with reduced skeletal muscle performance and poor outcome [21, 22]. Although GH administration produced beneficial effects on muscle strength in healthy men [23], its effects on cardiac remodeling have been poorly addressed. Results of therapeutic correction have been inconsistent, with some studies reporting unchanged functional cardiac indices [24], and others reporting improved left ventricular (LV) function, N-terminal prohormone brain natriuretic peptide (NT-proBNP) levels, and quality of life [19, 25].

Despite a potentially beneficial role on skeletal muscle, few authors have evaluated the effects of $\mathrm{GH}$ during heart failure [26]. In a previous study, we observed that GH preserved trophicity and attenuated interstitial fibrosis in aortic stenosis rat soleus muscle [27]. Also, $\mathrm{GH}$ prevented atrophy, apoptosis, and changes in myosin heavy chain in right heart failure [28, 29]. In this study, we tested the hypothesis that GH treatment improves muscle trophicity by activating satellite cells and the intracellular signaling pathways involved in muscular response to $\mathrm{GH}$. Therefore, the main focus of this study was to evaluate the effects of $\mathrm{GH}$ administration on soleus muscle of rats with chronic heart failure induced by aortic stenosis. The effects of treatment on cardiac structures and left ventricular function were also assessed.

\section{RESULTS}

\section{General characteristics of rats}

In the AS group ( $n=13), 12$ animals had tachypnea/ labored respiration, 8 ascites, 7 pleuropericardial effusion, 6 thrombi in atria, 13 right ventricular hypertrophy, and 12 lung congestion. In AS-GH $(n=10)$, 8 rats presented tachypnea/labored respiration, 4 ascites, 7 pleuropericardial effusion, 7 thrombi in atria, 6 right ventricular hypertrophy, and 8 lung congestion. The frequency of heart failure features did not differ statistically between groups. There was no evidence of heart failure in the Sham group $(n=17)$. Anatomical data are shown in Table 1. 
Table 2: Pre-treatment echocardiographic data

\begin{tabular}{|c|c|c|c|}
\hline Variable & $\begin{array}{c}\text { Sham } \\
(n=17)\end{array}$ & $\begin{array}{c}\text { AS } \\
(n=13)\end{array}$ & $\begin{array}{c}\text { AS-GH } \\
(n=10)\end{array}$ \\
\hline BW (g) & $508.4 \pm 41.1$ & $451.7 \pm 89.7$ & $466.7 \pm 59.5$ \\
\hline LVDD (mm) & $8.08 \pm 0.45$ & $8.51 \pm 1.10$ & $8.64 \pm 0.82$ \\
\hline LVDD/BW (mm/kg) & $15.98 \pm 1.21$ & $19.29 \pm 3.70 *$ & $18.69 \pm 1.98 *$ \\
\hline LVSD (mm) & $3.77 \pm 0.47$ & $4.07 \pm 1.24$ & $3.86 \pm 0.90$ \\
\hline PWDT (mm) & $1.47 \pm 0.09$ & $2.25 \pm 0.34^{*}$ & $2.46 \pm 0.24 *$ \\
\hline PWST (mm) & $2.98 \pm 0.21$ & $3.98 \pm 0.34^{*}$ & $4.37 \pm 0.72 *$ \\
\hline IVSST (mm) & $2.67 \pm 0.20$ & $3.25 \pm 0.24 *$ & $3.59 \pm 0.27 * \#$ \\
\hline IVSDT (mm) & $1.48 \pm 0.08$ & $2.26 \pm 0.34^{*}$ & $2.48 \pm 0.26^{*}$ \\
\hline $\mathrm{AO}(\mathrm{mm})$ & $3.80 \pm 0.21$ & $3.91 \pm 0.27$ & $3.93 \pm 0.37$ \\
\hline $\mathbf{L A}(\mathbf{m m})$ & $4.99 \pm 0.34$ & $7.82 \pm 1.08 *$ & $7.72 \pm 0.87 *$ \\
\hline LA/AO & $1.32 \pm 0.15$ & $2.00 \pm 0.28 *$ & $1.97 \pm 0.21 *$ \\
\hline LA/BW (mm/kg) & $9.88 \pm 1.07$ & $17.79 \pm 3.73^{*}$ & $16.68 \pm 1.93 *$ \\
\hline LVRWT & $0.35 \pm 0.03$ & $0.52 \pm 0.11 *$ & $0.53 \pm 0.04 *$ \\
\hline HR (bpm) & $287 \pm 41$ & $299 \pm 34$ & $299 \pm 40$ \\
\hline EFS (\%) & $53.4 \pm 4.4$ & $53.0 \pm 9.5$ & $55.5 \pm 8.5$ \\
\hline MWFS (\%) & $30.3 \pm 3.1$ & $28.7 \pm 4.3$ & $29.5 \pm 3.9$ \\
\hline LVEF & $0.89 \pm 0.03$ & $0.89 \pm 0.06$ & $0.90 \pm 0.05$ \\
\hline $\operatorname{PWSV}(\mathrm{mm} / \mathbf{s})$ & $37.0 \pm 2.5$ & $27.8 \pm 4.6^{*}$ & $28.7 \pm 6.3^{*}$ \\
\hline E-wave & $73 \pm 7.0$ & $141 \pm 13.8^{*}$ & $122 \pm 17.5^{*}$ \\
\hline A-wave & $48 \pm 6.7$ & $34 \pm 23.4^{*}$ & $25 \pm 6.0^{*}$ \\
\hline $\mathbf{E} / \mathbf{A}$ & $1.58 \pm 0.35$ & $4.86 \pm 1.31^{*}$ & $5.25 \pm 2.03 *$ \\
\hline EDT (ms) & $50 \pm 6.9$ & $33 \pm 8.4^{*}$ & $34 \pm 10.6^{*}$ \\
\hline IVRT (ms) & $31 \pm 5.44$ & $24 \pm 7.61 *$ & $21 \pm 6.32 *$ \\
\hline IVRTn (ms) & $33 \pm 4.4$ & $23 \pm 4.7 *$ & $19 \pm 5.2 *$ \\
\hline
\end{tabular}

Data are expressed as mean \pm standard deviation. AS: aortic stenosis; AS-GH: aortic stenosis treated with growth hormone; n: number of animals; BW: body weight; LVDD and LVSD: left ventricle (LV) diastolic and systolic diameters, respectively; PWDT and PWST: LV posterior wall diastolic and systolic thicknesses, respectively; IVSST and IVSDT: interventricular septum systolic and diastolic thicknesses, respectively; AO: aortic diameter; LA: left atrial diameter; LVRWT: LV relative wall thickness; HR: heart rate (beats/min); EFS: endocardial fractional shortening; MWFS: midwall fractional shortening; LVEF: LV ejection fraction; PWSV: LV posterior wall shortening velocity; E/A: early-to-late diastolic mitral inflow ratio; EDT: E-wave deceleration time; IVRT: isovolumetric relaxation time; IVRTn: IVRT normalized to heart rate. ANOVA and Tukey; * $\mathrm{p}<0.05$ vs Sham; \# $\mathrm{p}<0.05$ vs AS.

\section{Echocardiographic evaluation}

Before treatment, both AS groups had similar echocardiographic variables values, except for interventricular septum systolic thickness, which was higher in AS-GH than AS (Table 2). Final echocardiographic data are shown in Table 3. Due to technical problems, we could not perform final echocardiogram in two Sham rats and two AS-GH rats. Body weight was lower in AS than Sham and AS-GH. LV diastolic diameter-to-body weight ratio was higher in AS than Sham and AS-GH and did not differ between AS-GH and Sham. Diastolic and systolic posterior wall and interventricular septum thickness and left atria diameter were higher in both AS groups than Sham. Systolic interventricular septum thickness remained higher in AS-GH than AS. Endocardial fractional shortening was 
Table 3: Post-treatment echocardiographic data

\begin{tabular}{|c|c|c|c|}
\hline Variables & $\begin{array}{l}\text { Sham } \\
(n=15)\end{array}$ & $\begin{array}{c}\text { AS } \\
(n=13)\end{array}$ & $\begin{array}{c}\text { AS-GH } \\
(n=08)\end{array}$ \\
\hline BW (g) & $484 \pm 42$ & $415 \pm 31^{*}$ & $476 \pm 58^{\#}$ \\
\hline LVDD (mm) & $7.73 \pm 0.53$ & $7.93 \pm 1.42$ & $7.98 \pm 1.02$ \\
\hline LVDD/BW (mm/kg) & $15.54 \pm 1.45$ & $18.47 \pm 3.20 *$ & $16.53 \pm 3.62^{\#}$ \\
\hline LVSD (mm) & $3.16 \pm 0.51$ & $4.08 \pm 1.74$ & $3.20 \pm 0.91$ \\
\hline PWDT (mm) & $1.43 \pm 0.09$ & $2.25 \pm 0.25^{*}$ & $2.41 \pm 0.37^{*}$ \\
\hline PWST (mm) & $3.03 \pm 0.21$ & $3.79 \pm 0.48^{*}$ & $4.33 \pm 0.63^{*}$ \\
\hline IVSST (mm) & $2.80 \pm 0.19$ & $3.05 \pm 0.26^{*}$ & $3.44 \pm 0.30^{* \#}$ \\
\hline IVSDT (mm) & $1.45 \pm 0.08$ & $2.26 \pm 0.24 *$ & $2.40 \pm 0.35^{*}$ \\
\hline $\mathrm{AO}(\mathrm{mm})$ & $3.9 \pm 0.1$ & $4.1 \pm 0.2^{*}$ & $4.0 \pm 0.2$ \\
\hline $\mathbf{L A}(\mathbf{m m})$ & $4.9 \pm 0.2$ & $7.0 \pm 0.8^{*}$ & $7.8 \pm 1.2^{*}$ \\
\hline LA/AO & $1.28 \pm 0.06$ & $1.74 \pm 0.19 *$ & $1.92 \pm 0.30^{*}$ \\
\hline LA/BW (mm/kg) & $9.89 \pm 0.79$ & $16.22 \pm 1.68^{*}$ & $15.87 \pm 2.08 *$ \\
\hline LVRWT & $0.37 \pm 0.03$ & $0.58 \pm 0.10 *$ & $0.62 \pm 0.16^{*}$ \\
\hline HR (bpm) & $303 \pm 43$ & $298 \pm 27$ & $308 \pm 21$ \\
\hline $\operatorname{EFS}(\%)$ & $59.1 \pm 5.6$ & $49.8 \pm 14.7^{*}$ & $59.8 \pm 12.1^{\#}$ \\
\hline MWFS (\%) & $32.8 \pm 3.2$ & $26.6 \pm 7.9 *$ & $31.6 \pm 6.3$ \\
\hline LVEF & $0.93 \pm 0.03$ & $0.87 \pm 0.10$ & $0.92 \pm 0.08$ \\
\hline PWSV (mm/s) & $38.6 \pm 7.2$ & $25.2 \pm 5.1^{*}$ & $25.6 \pm 3.1^{*}$ \\
\hline E-wave & $74 \pm 8.5$ & $132 \pm 15.7^{*}$ & $121 \pm 19.0 *$ \\
\hline A-wave & $55 \pm 15.9$ & $26 \pm 5.0^{*}$ & $23 \pm 5.8^{*}$ \\
\hline $\mathbf{E} / \mathbf{A}$ & $1.45 \pm 0.37$ & $5.23 \pm 0.97 *$ & $5.59 \pm 1.31^{*}$ \\
\hline EDT (ms) & $53 \pm 4.3$ & $33 \pm 4.8^{*}$ & $29 \pm 5.9^{*}$ \\
\hline IVRT (ms) & $33 \pm 4.18$ & $24 \pm 4.70^{*}$ & $21 \pm 5.77^{*}$ \\
\hline IVRTn (ms) & $34 \pm 4.3$ & $23 \pm 5.0 *$ & $21 \pm 5.5^{*}$ \\
\hline
\end{tabular}

Data are expressed as mean \pm standard deviation. AS: aortic stenosis; AS-GH: aortic stenosis treated with growth hormone; n: number of animals; ; LVDD and LVSD: left ventricle (LV) diastolic and systolic diameters, respectively; PWDT and PWST: LV posterior wall diastolic and systolic thicknesses, respectively; IVSST and IVSDT: interventricular septum systolic and diastolic thicknesses, respectively; AO: aortic diameter; LA: left atrial diameter; LVRWT: LV relative wall thickness; HR: heart rate (beats/min); EFS: endocardial fractional shortening; MWFS: midwall fractional shortening; LVEF: LV ejection fraction; PWSV: LV posterior wall shortening velocity; E/A: early-to-late diastolic mitral inflow ratio; EDT: E-wave deceleration time; IVRT: isovolumetric relaxation time; IVRTn: IVRT normalized to heart rate. ANOVA and Tukey; * $\mathrm{p}<0.05$ vs Sham; \# $<<0.05$ vs AS.

lower in AS than Sham and AS-GH, and midwall fractional shortening was lower in AS than Sham. Posterior wall shortening velocity, A-wave, E-wave deceleration time, and isovolumetric relaxation time were lower in both AS and AS-GH than Sham. E-wave and E/A ratio were higher in AS and AS-GH than Sham.

\section{Histologic analysis}

Figure 1A illustrates hematoxylin-eosin stained sections of soleus muscle. Soleus fiber cross-sectional area was smaller in both AS groups than Sham and did not differ between AS-GH and AS (Sham 3,556 4447 ; AS $2,882 \pm 422$; AS-GH 2,868 $\pm 591 \mu \mathrm{m}^{2} ; \mathrm{p}=0.016$ AS and ASGH vs Sham; Figure 1B).

\section{Immunofluorescence}

In soleus muscle, neural cell adhesion molecule (NCAM) staining was higher in both AS groups than Sham and did not differ between AS-GH and AS (Sham $0.50 \pm 0.76$; AS 2.25 \pm 1.04 ; AS-GH $3.38 \pm 0.92$ arbitrary 
units; $\mathrm{p}<0.001$ AS and AS-GH vs Sham; Figure 2). MyoD [Sham 1.00 (0.00-2.00); AS 2.50 (2.00-3.00); AS-GH 2.50 (1.00-3.50) arbitrary units; $\mathrm{p}=0.14]$ and neonatal myosin heavy chain [Sham 0.00; AS 0.50 (0.00-1.00); AS-GH $0.50(0.00-2.00)$ arbitrary units; $p=0.19$ ] staining did not differ between groups.

\section{Circulating IGF-1 levels}

IGF-1 serum levels were higher in AS-GH than the other two groups (Sham 938 \pm 83 ; AS $866 \pm 116$; AS-GH $1167 \pm 166$ ng/mL; $<<0.0001$; Figure 3A).

\section{Protein expression}

IGF-1 protein expression was higher in AS-GH than the other groups (Sham 1.00 \pm 0.25 ; AS 0.96 \pm 0.46 ; AS-GH $1.67 \pm 0.45$ arbitrary units; $\mathrm{p}=0.004$; Figure $3 \mathrm{~B}$ ). Phosphorylated-PI3K was higher in AS and AS-GH than Sham (Sham 0.94 (0.74-1.28); AS 3.99 (3.01-5.46); ASGH 3.71 (1.97-9.62) arbitrary units; $p=0.004)$; total PI3K was higher in AS-GH than Sham (Sham 0.98 (0.63-1.32); AS 1.26 (1.00-2.51); AS-GH 2.51 (2.07-6.05) arbitrary units; $p=0.037$; Figure 4$)$. The other proteins did not differ between groups (Table 4 and Supplementary Figure 1).

\section{DISCUSSION}

In this study, we evaluated the effects of growth hormone administration on satellite cell activation and intracellular signaling pathways related to skeletal muscle trophism in the soleus muscle of rats with aortic stenosisinduced heart failure.

Ascending aortic stenosis in rats is a useful model for studying pressure overload-induced heart failure. Three-to-four week-old rats have a clip placed around the ascending aorta. After clip placement, aorta diameter is preserved; as rats grow, stenosis progressively develops. The model has the advantage that, despite rapid onset of LV hypertrophy, LV dysfunction occurs slowly [30, 31 ], similar to that observed in human chronic pressure overload. Congestive heart failure is usually observed from 18 weeks after stenosis induction [27, 30, 32].

Before treatment, aortic stenosis rats presented left atrial dilation and LV hypertrophy with systolic and diastolic dysfunction. GH treatment attenuated systolic dysfunction as endocardial fractional shortening was higher in AS-GH than AS. Furthermore, midwall fractional shortening was lower in AS than Sham, but did not differ between AS-GH and Sham. The increased LV relative wall thickness in AS and AS-GH shows that both aortic stenosis

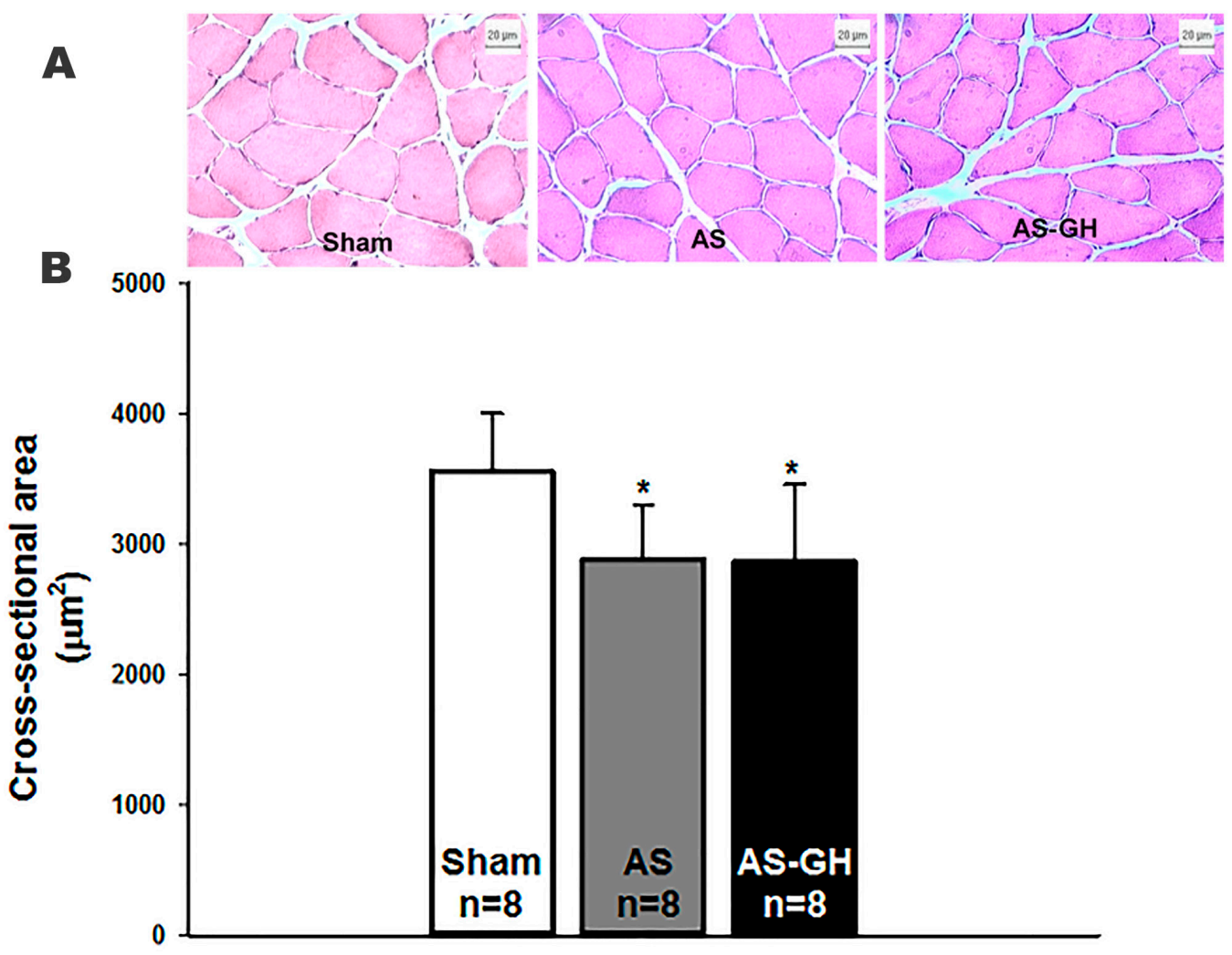

Figure 1: Photomicrographs of soleus muscle cross-sections stained with haematoxylin-eosin (A). Soleus muscle cross-sectional area (B). AS: aortic stenosis; AS-GH: aortic stenosis treated with growth hormone; n: number of animals. Data are expressed as mean \pm standard deviation. ANOVA and Tukey; * $\mathrm{p}<0.05$ vs Sham. 
groups had LV concentric hypertrophy. Heart failure was established by clinical and pathological features evaluated in vivo and post mortem. Lung weight and right ventricular hypertrophy are often used to diagnose heart failure in rats [33]. In this study, heart failure feature frequencies did not differ between AS-GH and AS groups. Therefore, despite attenuating systolic dysfunction, late $\mathrm{GH}$ administration did not modulate heart failure severity in aortic stenosis rats. The late treatment may have prevented differences in heart failure features between groups.

GH and IGF-1 play essential role in cardiac growth and performance [34]. Chronic administration of $\mathrm{GH}$
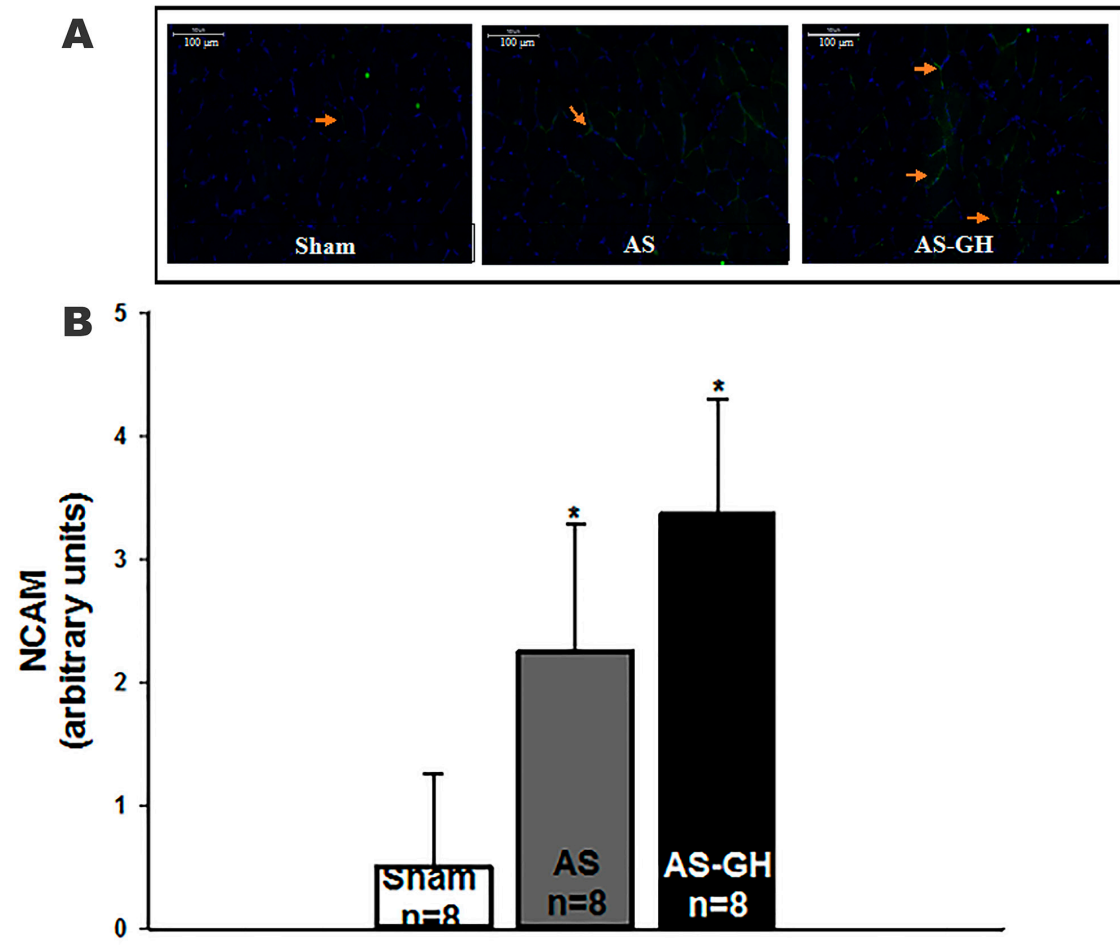

Figure 2: Representative immunofluorescence of soleus muscle cross-sections stained with anti-neural cell adhesion molecule (NCAM) and 4',6-diamidino-2-phenylindole (DAPI) showing cell nucleus in blue and neural cell adhesion molecule (NCAM) in green (A). Quantification of staining intensity of NCAM (B). AS: aortic stenosis; AS-GH: aortic stenosis treated with growth hormone; n: number of animals. Data are expressed as mean \pm standard deviation; ANOVA and Tukey; ${ }^{*} \mathrm{p}<0.05$ vs Sham.
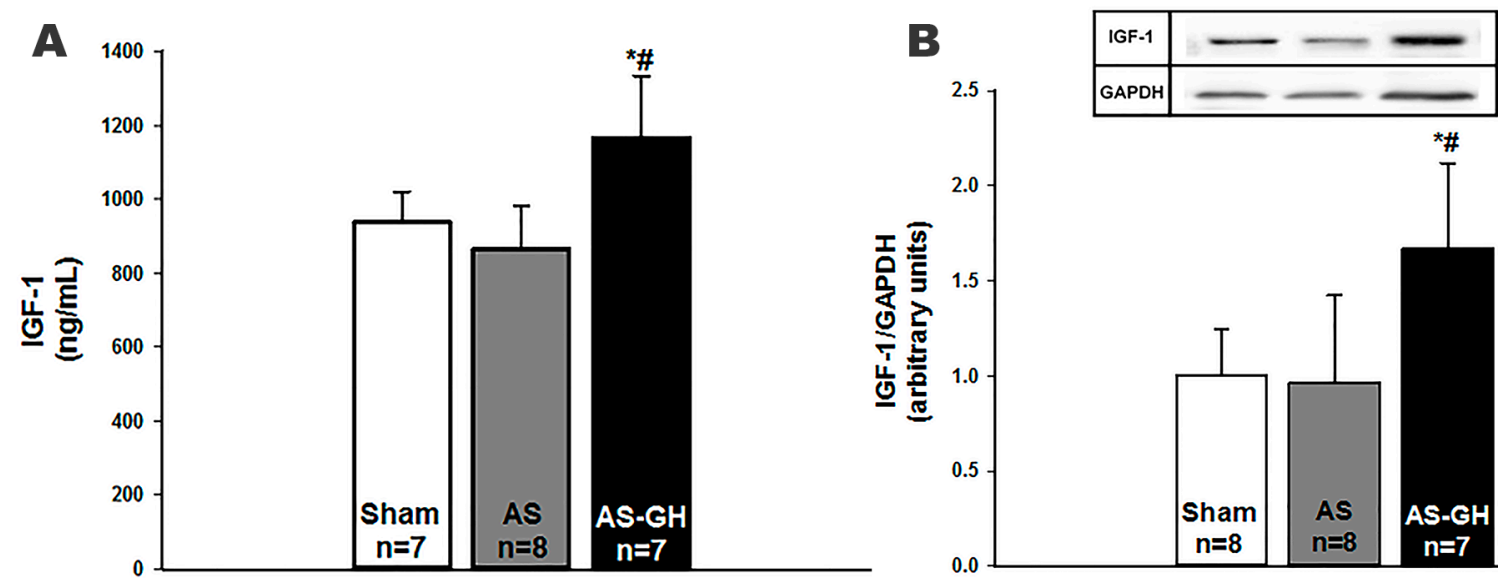

Figure 3: Insulin-like growth factor (IGF)-1: serum levels (A) and soleus muscle protein expression (B). AS: aortic stenosis; AS-GH: aortic stenosis treated with growth hormone; n: number of animals. Data are expressed as mean \pm standard deviation. ANOVA and Tukey; * $\mathrm{p}<0.05$ vs Sham; $\# \mathrm{p}<0.05$ vs AS. 
to normal rodents induces myocyte hypertrophy and improves cardiac performance [35]. However, in failing hearts, the effects of $\mathrm{GH}$ are still controversial [26, 32, 36-38]. We have previously observed that short-term GH treatment induces cardioprotection by attenuating myocardial fibrosis and systolic dysfunction in aortic stenosis rats [32]. In a small trial of heart failure patients with GH deficiency, GH replacement for 4 years improved peak oxygen consumption and systolic function with no major adverse events [25]. Therefore, our data reinforces the potential beneficial role of $\mathrm{GH}$ on cardiac remodeling and LV dysfunction.
In this study, GH preserved body weight. A similar result was reported post-myocardial infarction [26]. Cardiac cachexia is often observed in advanced stages of heart failure [39] and is associated with poor prognosis $[40,41]$. Therefore, the effect of GH in preventing body mass loss may be important for heart failure prognosis. Although body weight preservation may suggest skeletal muscle preservation, this did not occur in soleus muscle. Atrophy of soleus muscle is a common finding in different experimental heart failure models $[30,42,43]$.

As expected, GH increased both IGF-1 serum concentration and IGF-1 soleus protein expression. IGF-

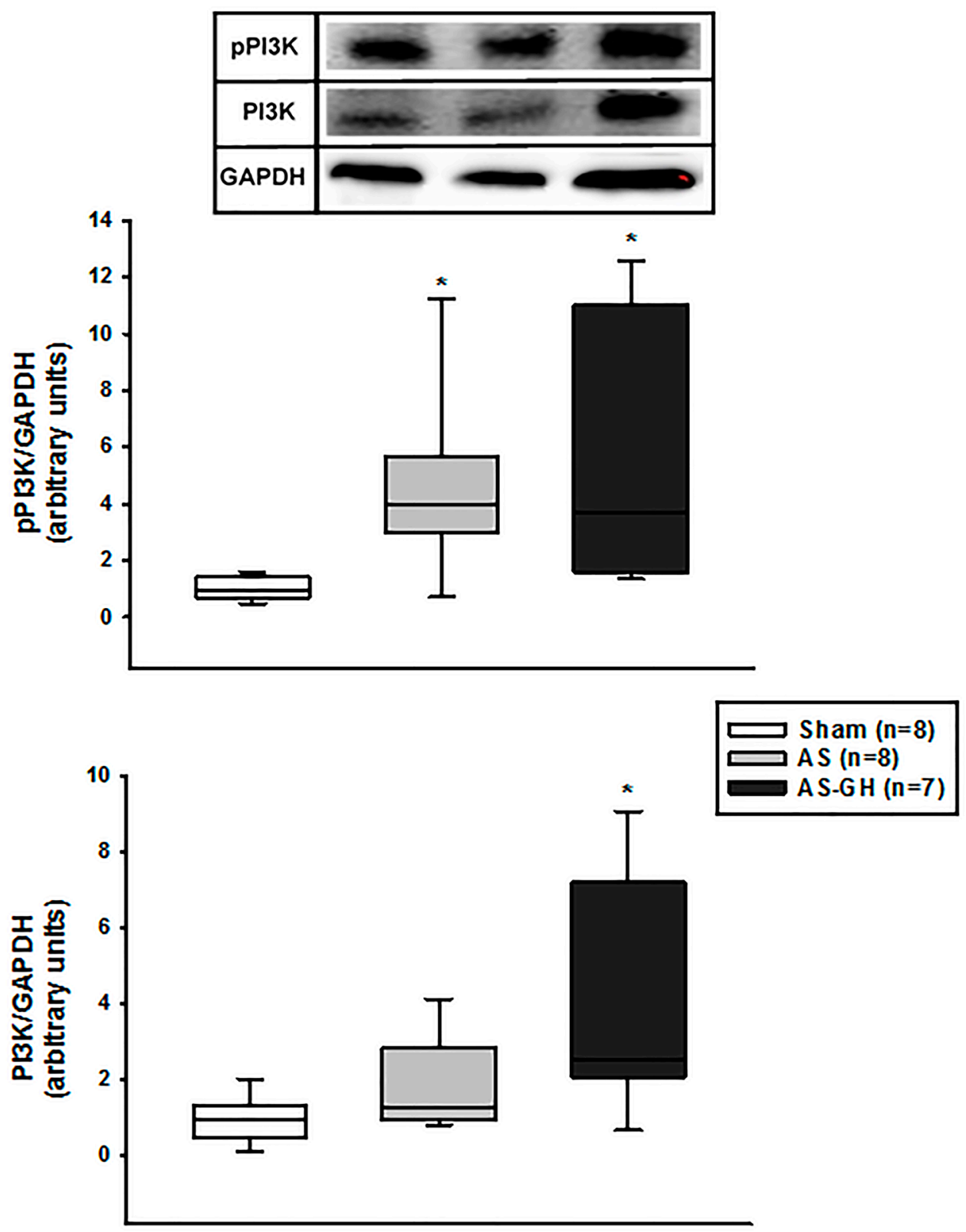

Figure 4: Phosphorylated phosphatidylinositol-3-kinase (PI3K) and total PI3K protein expression in soleus muscle assessed by Western blot. AS: aortic stenosis; AS-GH: aortic stenosis treated with growth hormone; n: number of animals. Data are expressed as median and percentiles; Kruskal-Wallis and Student-Newman-Keuls; * $\mathrm{p}<0.05$ vs Sham. 
Table 4: Protein expression

\begin{tabular}{lccc}
\hline $\begin{array}{l}\text { Proteins } \\
\text { (arbitrary units) }\end{array}$ & $\begin{array}{c}\text { Sham } \\
(\mathbf{n = 0 8})\end{array}$ & $\begin{array}{c}\text { AS } \\
(\mathbf{n}=\mathbf{0 8})\end{array}$ & $\begin{array}{c}\text { AS-GH } \\
(\mathbf{n}=\mathbf{0 7})\end{array}$ \\
\hline MyoD & $1.04(0.88-1.13)$ & $1.10(0.90-1.42)$ & $1.47(1.11-1.79)$ \\
Myogenin & $1.00 \pm 0.38$ & $0.58 \pm 0.36$ & $0.87 \pm 0.68$ \\
MRF4 & $0.88(0.62-1.35)$ & $0.60(0.34-1.19)$ & $1.33(0.79-3.27)$ \\
Akt & $1.00 \pm 0.54$ & $0.86 \pm 0.35$ & $0.86 \pm 0.54$ \\
Atrogin-1 & $1.00 \pm 0.44$ & $0.73 \pm 0.19$ & $0.92 \pm 0.18$ \\
MuRF-1 & $1.00 \pm 0.90$ & $0.53 \pm 0.41$ & $0.63 \pm 0.23$ \\
Myostatin & $1.00 \pm 0.32$ & $1.86 \pm 1.09$ & $2.05 \pm 1.07$ \\
Follistatin & $1.00 \pm 1.11$ & $1.42 \pm 0.83$ & $1.06 \pm 0.63$ \\
Pax-7 & $1.00 \pm 0.39$ & $0.74 \pm 0.63$ \\
\hline
\end{tabular}

Data are expressed as mean \pm standard deviation or median and percentiles. AS: aortic stenosis; AS-GH: aortic stenosis treated with growth hormone; n: number of animals. ANOVA and Tukey or Kruskal-Wallis and Student-Newman-Keuls; $\mathrm{p}>0.05$ for all proteins.

1 binding to its receptors activates several intracellular kinases. PI3K is a well-known signal transduction pathway activated by GH $[44,45]$. Total PI3K expression was higher in AS-GH than Sham and phosphorylated-PI3K was higher in both AS groups than Sham. Akt/mTOR acts as IGF1 downstream mediators [45]. Down-stimulation of Akt activates the forkhead box protein $\mathrm{O}$ (FoxO) family which increases atrogin-1 and MuRF-1, two potent inducers of protein degradation [7, 45-48]. It was therefore unexpected to observe that, despite activating IGF-1 and PI3K, GH failed to modulate atrogin- 1 and MuRF-1 expression. Muscle atrophy is caused by the limitation of anabolic processes and/or activation of intracellular proteolytic systems [7]. In heart failure, proteolysis appears to overcome impaired protein synthesis $[31,54,55]$. We observed that the catabolic pathways evaluated in this study were not activated in rats with aortic stenosis-induced heart failure.

The myostatin/follistatin pathway has attracted increasing attention as a modulator of skeletal muscle mass $[45,49,50]$. Myostatin negatively regulates muscle size and follistatin acts as a myostatin antagonist. Balance between these two proteins is important in maintaining skeletal muscle mass [51]. Despite muscle atrophy in aortic stenosis rats, myostatin and follistatin expression did not differ between groups and was not changed by GH. In a previous study on infarcted rats, we observed that skeletal muscle atrophy was combined with preserved myostatin and reduced follistatin expression [43]. This study therefore showed that aortic stenosis-induced muscle atrophy is not associated with myostatin/follistatin changes.

Several molecular markers have been used to evaluate satellite cell activation; these include NCAM, MyoD, neonatal myosin heavy chain, and Pax-7 [13, 52,
53]. In this study, satellite cell activation was observed by increased NCAM staining in both the AS and AS-GH groups. Activation of quiescent satellite cells is related to cell proliferation and differentiation [13, 14]. We therefore showed that satellite cells are activated during heart failure and not modulated by $\mathrm{GH}$ administration.

Myogenic regulatory factors $\mathrm{MyoD}$, myogenin, and MRF4 modulate the expression of several muscle proteins. In this study, their expression did not differ between groups. We have previously observed in aortic stenosis rats that GH increased soleus MyoD expression, preserved muscle trophicity, and attenuated interstitial fibrosis [27]. These rats however had a lower degree of cardiac injury as LV was not dilated and LV function was preserved except for a reduced $\mathrm{LV}$ posterior wall shortening velocity. It is therefore probable that $\mathrm{GH}$ produces beneficial effects in non-severe heart failure.

In summary, our results showed that late administration of $\mathrm{GH}$, despite attenuating systolic dysfunction, failed to prevent/reverse soleus muscle atrophy. In fact, in disagreement with our hypothesis, GH did not modulate muscle trophism, satellite cell activation or the intracellular signaling pathways evaluated in this study. As GH preserved body weight, increased serum and muscular IGF-1 levels, and stimulated PI3K muscle expression, this study allowed us to raise two hypotheses: GH was initiated later when muscle atrophy was already established; or GH treatment was not long enough to reverse the muscle atrophy process. Therefore, although this study adds important information on the use of GH during heart failure, it was not possible to establish the best stage of heart failure to start $\mathrm{GH}$ in order to prevent/reverse skeletal muscle atrophy. 
In conclusion, short-term growth hormone treatment attenuates left ventricular systolic dysfunction in rats with aortic stenosis-induced heart failure. Despite preserving body weight, increasing serum and muscular IGF-1 levels, and stimulating PI3K muscle expression, growth hormone does not modulate soleus muscle trophism, satellite cell activation, or the intracellular pathways associated with muscle catabolism.

\section{MATERIALS AND METHODS}

\section{Experimental groups}

Male Wistar rats (90-100 g) were purchased from the Central Animal House, Botucatu Medical School, Sao Paulo State University, UNESP, Botucatu, Brazil. Commercial chow and water were supplied ad libitum. Animals were housed in a room under temperature and light control in collective cages with four rats per cage. All experiments and procedures were approved by the Ethics Committee of Botucatu Medical School, Sao Paulo State University.

Aortic-stenosis was induced as previously described [56]. In summary, the animals were subjected to median thoracotomy after intramuscular anesthesia with ketamine hydrochloride $(50 \mathrm{mg} / \mathrm{kg})$ and xylazine hydrochloride (10 $\mathrm{mg} / \mathrm{kg}$ ). After dissecting the ascending aorta, a $0.6 \mathrm{~mm}$ stainless-steel clip was placed at approximately $3 \mathrm{~mm}$ from the aorta root. During surgery, the rats were manually ventilated using positive pressure and given $1 \mathrm{~mL}$ of warm saline solution intraperitoneally. Sham operated rats were used as controls.

We have previously observed that aortic stenosis rats start to present clinical heart insufficiency approximately 18 to 28 weeks after the surgery $[27,30,57]$. Therefore, beginning 18 weeks after surgery, rats were observed twice a week to detect heart failure signs, such as tachypnea and weight loss $[58,59]$. After observing these features, rats were subjected to transthoracic echocardiogram to evaluate degree of cardiac injury, and randomly assigned to two groups: aortic stenosis with no treatment (AS), and aortic stenosis treated with GH (AS-GH). Rats were given daily subcutaneous injections of recombinant human growth hormone ( $2 \mathrm{mg} / \mathrm{kg} /$ day; Novo-Nordisk Laboratory, Bagsvaerd, Denmark) or vehicle for 14 days. Age-matched Sham rats were studied at comparable ages.

At the time of euthanasia, we evaluated the presence of anatomical heart failure features such as atria thrombi, ascites, pleuropericardial effusion, lung congestion (lung weight-to-body weight ratio $>2$ standard deviations above Sham group mean), and right ventricular hypertrophy (right ventricle weight-to-body weight ratio greater than $0.8 \mathrm{mg} / \mathrm{g}$ ) [60]. Aortic stenosis-induced cardiac remodeling was characterized by echocardiographic parameters. GHinduced increase in IGF-1 levels was determined by assessing its systemic concentration and muscular protein expression.

\section{Echocardiography}

Echocardiographic evaluation was performed using a commercially available echocardiograph (General Electric Medical Systems, Vivid S6, Tirat Carmel, Israel) equipped with a 5-11.5 $\mathrm{MHz}$ multifrequency probe, as previously described [61-63]. Rats were anesthetized by intramuscular injection of a mixture of ketamine $(50 \mathrm{mg} / \mathrm{kg})$ and xylazine $(0.5 \mathrm{mg} / \mathrm{kg})$. A twodimensional parasternal short-axis view of the LV was obtained at the level of the papillary muscles. M-mode tracings were obtained from short-axis views of the LV at or just below the tip of the mitral-valve leaflets, and at the level of the aortic valve and left atrium. M-mode images of the LV were printed on a black-and-white thermal printer (Sony UP-890MD) at a sweep speed of $100 \mathrm{~mm} / \mathrm{s}$. All LV structures were manually measured by the same observer $(\mathrm{KO})$. Values obtained were the mean of at least five cardiac cycles on M-mode tracings. The following structural variables were measured: LV diastolic and systolic diameters (LVDD and LVSD, respectively), LV posterior wall diastolic and systolic thicknesses (PWDT and PWST, respectively), interventricular septum systolic and diastolic thicknesses (IVSST and IVSDT, respectively), left atrial diameter (LA), and aortic diameter (AO). LV relative wall thickness (LVRWT) was calculated as $2 \mathrm{X}$ PWDT/LVDD. LV function was assessed by the following parameters: endocardial fractional shortening (EFS), midwall fractional shortening (MWFS), LV posterior wall shortening velocity (PWSV), early and late diastolic mitral inflow velocities ( $\mathrm{E}$ and $\mathrm{A}$ waves, respectively), E/A ratio, E-wave deceleration time (EDT), isovolumetric relaxation time (IVRT), and IVRT normalized to heart rate (IVRTn).

\section{Morphological analysis}

At euthanasia, rats were weighed and anesthetized with intraperitoneal sodium pentobarbital $(50 \mathrm{mg} / \mathrm{kg})$. Hearts were removed by thoracotomy and the atria and ventricles were separated and weighed. Soleus muscle was dissected, weighed, immediately frozen in liquid nitrogen, and stored at $-80^{\circ} \mathrm{C}$.

Transverse sections approximately $8-10 \mu \mathrm{m}$ thick of frozen soleus were cut in a cryostat at $-20{ }^{\circ} \mathrm{C}$ and stained with hematoxylin and eosin. Muscle trophicity was assessed by measuring at least 200 cross-sectional fiber areas from each muscle [64]. Measurements were performed using a compound LEICA DM LS microscope attached to a computerized imaging analysis system (Media Cybernetics, Silver Spring, Maryland, USA). All analysis were performed by the same blind investigator. 


\section{Immunofluorescence}

We next evaluated the following molecular markers of satellite cell activation by immunofluorescence: NCAM, MyoD and neonatal myosin heavy chain. Soleus muscle transverse sections were fixed in $4 \%$ paraformaldehyde dissolved in phosphate-saline buffer (PBS), for $10 \mathrm{~min}$ at room temperature. Sections were then washed in PBS, blocked in PBS-albumin bovine serum (BSA) 5\%-Triton $\mathrm{X}-100$ for $10 \mathrm{~min}$, and blocked again in PBS with 5\% BSA for a further $20 \mathrm{~min}$. Sections were incubated overnight in primary antibody (anti-NCAM, H-300 sc10735; anti-MyoD, M-318 sc-760; and anti-neonatal myosin, N1.551 sc-53097; Santa Cruz Biotechnology, Santa Cruz, CA, USA) diluted in PBS, at $4{ }^{\circ} \mathrm{C}$. Sections were then incubated with secondary antibody for one hour in a dark chamber at room temperature. Next, sections were washed in PBS, incubated with DAPI, and washed again in PBS. Coverslips were allocated using ProLong $\mathbb{R}$ Gold Antifade reagent (Molecular Probes ${ }^{\circledR}$ by Life Technologies). Sections were analyzed in fluorescence microscope (Olympus BX51, equipped with an Olympus U-RFL-T fluorescence emitter and Olympus DP72 camera, Panasonic). We evaluated 10 histologic frames in each section. Immunofluorescence reaction was analyzed for staining intensity according to pre-established scores: +++ strong, ++ moderate, + weak or - without staining.

\section{Western blotting}

Soleus protein levels were analyzed by Western blot according to a previously described method [65, 66]. Protein expression of myogenic regulatory factors (MyoD, M-318 sc-760; myogenin, M-225 sc-576e; MRF4, Myf-6 C-19 sc-301), IGF-1 (H-70 sc-9013), atrophy pathway related-proteins (PI3K, PI 3-kinase p85 $\alpha$ B-9 sc-1637; p-PI3K, p-PI 3-kinase p85 $\alpha$ (Tyr 467) sc-293115; Akt, Akt1 G-5 sc-55523; atrogin-1, MAFbx H-300 sc-33782; MuRF-1, H-145 sc-32920; myostatin, GDF-8 N-19-R sc-6885-R; and follistatin H-114 sc30194), and Pax-7 (Pax-3/7 H-208 sc-25409; Santa Cruz Biotechnology, Santa Cruz, CA, USA) was evaluated. Protein levels were normalized to GAPDH (6C5 sc-32233, Santa Cruz Biotechnology). Samples were separated on polyacrylamide gel and then transferred to a nitrocellulose membrane. After blockade, the membrane was incubated with primary antibodies overnight at $4{ }^{\circ} \mathrm{C}$. The membrane was then washed with PBS and Tween 20 and incubated with secondary peroxidase-conjugated antibody for 90 min at room temperature. ECL Western Blotting Substrate (Pierce Protein Research Products, Rockford, USA) was used to detect bound antibodies. The membrane was then stripped (Restore Western Blot Stripping Buffer, Pierce Protein Research Products, Rockford, USA) to remove previous antibody. After blockade, the membrane was incubated with anti-GAPDH antibody $[67,68]$.

\section{Circulating IGF-1 levels}

IGF-1 serum concentration was assessed by enzyme linked immunosorbent assay (ELISA) using Quantikine ${ }^{\circledR}$ ELISA Mouse/Rat IGF-I kit (R\&D Systems, Minneapolis, MN, USA). The procedure was performed according to manufacturer instructions.

\section{Statistical analysis}

Data are expressed as mean \pm standard deviation or median and percentiles. Comparisons between groups were performed by one-way analysis of variance (ANOVA) followed by the Tukey test for parametric data, or by Kruskal-Wallis test followed by Student-NewmanKeuls for non-parametric data. Heart failure feature frequencies were analyzed by the Goodman's test. The level of significance was set at $5 \%$.

\section{ACKNOWLEDGMENTS}

The authors are grateful to Jose Carlos Georgette for their technical assistance and Colin Edward Knaggs for English editing.

\section{CONFLICTS OF INTEREST}

The authors report no relationship that could be construed as a conflicts of interest.

\section{GRANT SUPPORT}

Financial support was provided by $\mathrm{CNPq}$ (Proc. $\mathrm{n}$. 306.770/2015-6 and 306857/2012-0), FAPESP (Proc. n. 2010/50084-8, 2009/54102-3, and 2012/50512-5), CAPES, and PROPe, UNESP.

\section{REFERENCES}

1. Brunjes DL, Kennel PJ, Schulze CP. Exercise capacity, physical activity, and morbidity. Heart Fail Rev. 2017; 22: 133-139.

2. Fulster S, Tacke M, Sandek A, Ebner N, Tschope C, Doehner W, Anker SD, von Haehling S. Muscle wasting in patients with chronic heart failure: results from the studies investigating co-morbidities aggravating heart failure (SICA-HF). Eur Heart J. 2013; 34: 512-519.

3. Okoshi MP, Capalbo RV, Romeiro FG, Okoshi K. Cardiac cachexia: perspectives for prevention and treatment. Arq Bras Cardiol. 2017; 108: 74-80.

4. Salomon F, Cuneo R, Sonksen PH. Growth hormone and protein metabolism. Horm Res. 1991; 36: 41-43.

5. Lewis AJ, Wester TJ, Burrin DG, Dauncey MJ. Exogenous growth hormone induces somatotrophic gene expression in neonatal liver and skeletal muscle. Am J Physiol Regul Integr Comp Physiol. 2000; 278: R838-R844. 
6. Bichell BA, Kikuchi K, Rotwein P. Growth hormone rapidly activates insulin-like growth factor-1 gene transcription in vivo. Mol Endocrinol. 1992; 6: 1899-1908.

7. Bonaldo P, Sandri M. Cellular and molecular mechanisms of muscle atrophy. Dis Model Mech. 2013; 6: 25-39.

8. Chia DJ. Minireview: mechanisms of growth hormonemediated gene regulation. Mol Endocrinol. 2014; 28: 1012-1025.

9. Chikani V, Ho KK. Action of GH on skeletal muscle function: molecular and metabolic mechanisms. J Mol Endocrinol. 2013; 52: R107-R123.

10. Brioche T, Kireev RA, Cuesta S, Gratas-Delamarche A, Tresguerres JA, Gomez-Cabrera MC, Viña J. Growth hormone replacement therapy prevents sarcopenia by a dual mechanism: improvement of protein balance and of antioxidant defenses. J Gerontol A Biol Sci Med Sci. 2014; 69: 1186-1198.

11. Yin H, Price F, Rudnicki MA. Satellite cells and the muscle stem cell niche. Physiol Rev. 2013; 93: 23-67.

12. Schultz E, McCormick KM. Skeletal muscle satellite cells. Rev Physiol Biochem Pharmacol. 1994; 123: 213-257.

13. Hawke TJ, Garry DJ. Myogenic satellite cells: physiology to molecular biology. J Appl Physiol. 2001; 91: 534-551.

14. Wozniak AC, Kong J, Bock E, Pilipowicz O, Anderson JE. Signaling satellite-cell activation in skeletal muscle: markers, models, stretch, and potential alternate pathways. Muscle Nerve. 2005; 31: 283-300.

15. Sacca L. Heart failure as a multiple hormonal deficiency syndrome. Circ Heart Fail. 2009; 2: 151-156.

16. Jankowska EA, Biel B, Majda J, Szklarska A, Lopuszanska M, Medras M, Anker SD, Banasiak W, Poole-Wilson PA, Ponikowski P. Anabolic deficiency in men with chronic heart failure: prevalence and detrimental impact on survival. Circulation. 2006; 114: 1829-1837.

17. Anker SD, Volterrani M, Pflaum CD, Strasburger CJ, Osterziel KJ, Doehner W, Ranke MB, Poole-Wilson PA, Giustina A, Dietz R, Coats AJ. Acquired growth hormone resistance in patients with chronic heart failure: implications for therapy with growth hormone. J Am Coll Cardiol. 2001; 38: 443-452.

18. Cicoira M, Kalra PR, Anker SD. Growth hormone resistance in chronic heart failure and its therapeutic implications. J Card Fail. 2003; 9: 219-226.

19. Cittadini A, Saldamarco L, Marra AM, Arcopinto M, Carlomagno G, Imbriaco M, Del Forno D, Vigorito C, Merola B, Oliveiro U, Fazio S, Saccà L. Growth hormone deficiency in patients with chronic heart failure and beneficial effects of its correction. J Clin Endocrinol Metab. 2009; 94: 3329-3336.

20. Kontoleon PE, Anastasiou-Nana MI, Papapetrou PD, Alexopoulos G, Ktenas V, Rapti AC, Tsagalou EP, Nanas JN. Hormonal profile in patients with congestive heart failure. Int J Cardiol. 2003; 87: 179-183.

21. Petretta M, Colao A, Sardu C, Scopacasa F, Marzullo P, Pivonello R, Fontanella L, de Caterina M, de Simone A,
Bonaduce D. NT-proBNP, IGF-1 and survival in patients with chronic heart failure. Growth Horm IGF Res. 2007; 17: 288-296.

22. Niebauer J, Pflaum CD, Clark AL, Strasburger CJ, Hooper J, Poole-Wilson PA, Coats AJ, Anker SD. Deficient insulinlike growth factor I in chronic heart failure predicts altered body composition, anabolic deficiency, cytokine and neurohormonal activation. J Am Coll Cardiol. 1998; 32: 393-397.

23. Tavares AB, Micmacher E, Biesek S, Assumpção R, Redorat R, Veloso U, Vaisman M, Farinatti PT, Conceição F. Effects of growth hormone administration on muscle strength in men over 50 years old. Int J Endocrinol. 2013; 2013: 942030 .

24. Isgaard J, Bergh CH, Caidahl K, Lomsky M, Hjalmarson A, Bengtsson BA. A placebo-controlled study of growth hormone in patients with congestive heart failure. Eur Heart J. 1998; 19: 1704-1711.

25. Cittadini A, Marra AM, Arcopinto M, Bobbio E, Salzano A, Sirico D, Napoli R, Colao A, Longobardi S, Baliga RR, Bossone E, Saccà L. Growth hormone replacement delays the progression of chronic heart failure combined with growth hormone deficiency: an extension of a randomized controlled single-blind study. JACC Heart Fail. 2013; 1: 325-330.

26. Palus S, von Haehling S, Doehner W, Datta R, Zhang J, Dong JZ, Culler MD, Anker SD, Springer J. Effect of application route of the ghrelin analog BIM-28131 (RM131) on body weight and body composition in a rat heart failure model. Int J Cardiol. 2013; 168: 2369-2374.

27. Santos DP, Okoshi K, Moreira VO, Seiva FR, Almeida FL, Padovani CR, Carvalho RF, Okoshi MP, Cicogna AC, Castro AV, Pai-Silva MD. Growth hormone attenuates skeletal muscle changes in experimental chronic heart failure. Growth Horm IGF Res. 2010; 20: 149-155.

28. Dalla Libera L, Ravara B, Volterrani M, Gobbo V, Barbera MD, Angelini A, Betto DD, Germinario E, Vescovo G. Beneficial effects of GH/IGF-1 on skeletal muscle atrophy and function in experimental heart failure. Am J Physiol Cell Physiol. 2004; 286: C138-C144.

29. Vescovo G, Ravara B, Gobbo V, Angelini A, Dalla Libera L. Skeletal muscle fibres synthesis in heart failure: role of PGC-1alpha, calcineurin and GH. Int J Cardiol. 2005; 104: 298-306.

30. Gomes MJ, Martinez PF, Campos DH, Pagan LU, Bonomo C, Lima AR, Damatto RL, Cezar MD, Damatto FC, Rosa CM, Garcia CM, Reyes DR, Fernandes AA, et al. Beneficial effects of physical exercise on functional capacity and skeletal muscle oxidative stress in rats with aortic stenosisinduced heart failure. Oxid Med Cell Longev. 2016; 2016: 8695716.

31. Souza RW, Piedade WP, Soares LC, Souza PA, Aguiar AF, Vechetti-Junior IJ, Campos DH, Fernandes AA, Okoshi K, Carvalho RF, Cicogna AC, Dal-Pai-Silva M. Aerobic exercise training prevents heart failure-induced skeletal 
muscle atrophy by anti-catabolic, but not anabolic actions. PLoS One. 2014; 9: e110020.

32. Moreira VO, Pereira CA, Silva MO, Felisbino SL, Cicogna AC, Okoshi K, Aragon FF, Padovani CR, Castro AV. Growth hormone attenuates myocardial fibrosis in rats with chronic pressure overload-induced left ventricular hypertrophy. Clin Exp Pharmacol Physiol. 2009; 36: 325-330.

33. Martinez PF, Okoshi K, Zornoff LA, Oliveira AS Jr, Campos DH, Lima AR, Damatto RL, Cezar MD, Bonomo C, Guizoni DM, Padovani CR, Cicogna AC, Okoshi MP. Echocardiographic detection of congestive heart failure in postinfarction rats. J Appl Physiol. 2011; 111: 543-551.

34. Sacca L, Cittadini A, Fazio S. Growth hormone and the heart. Endocr Rev. 1994; 15: 555-573.

35. Tanaka N, Ryoke T, Hongo M, Mao L, Rockman HA, Clark RG, Ross J Jr. Effects of growth hormone and IGF-1 on cardiac hypertrophy and gene expression in mice. Am J Physiol. 1998; 275: H393-H399.

36. Imanishi R, Ashizawa N, Ohtsuru A, Seto S, AkiyamaUchida Y, Kawano H, Kuroda H, Nakashima M, Saenko VA, Yamashita S, Yano K. GH suppresses TGF-betamediated fibrosis and retains cardiac diastolic function. Mol Cell Endocrinol. 2004; 218: 137-146.

37. Hongo M, Ryoke T, Schoenfeld J, Hunter J, Dalton N, Clark R, Lowe D, Chien K, Ross J Jr. Effects of growth hormone on cardiac dysfunction and gene expression in genetic murine dilated cardiomyopathy. Basic Res Cardiol. 2000; 95: 431-441.

38. Ryoke T, Gu Y, Mao L, Hongo M, Clark RG, Peterson KL, Ross J. Progressive cardiac dysfunction and fibrosis in the cardiomyopathic hamster and effects of growth hormone and angiotensin-converting enzyme inhibition. Circulation. 1999; 100: 1734-1743.

39. Molinari F, Malara N, Mollace V, Rosano G, Ferraro E. Animal models of cardiac cachexia. Int J Cardiol. 2016; 219: 105-110.

40. Okoshi MP, Romeiro FG, Paiva SA, Okoshi K. Heart failure-induced cachexia. Arq Bras Cardiol. 2013; 100: 476-482.

41. Anker SD, Negassa A, Coats AJ, Afzal R, Poole-Wilson PA, Cohn JN, Yusuf S. Prognostic importance of weight loss in chronic heart failure and the effect of treatment with angiotensin-converting-enzyme inhibitors: an observational study. Lancet. 2003; 361: 1077-1083.

42. Damatto RL, Martinez PF, Lima AR, Cezar MD, Campos DH, Oliveira SA Jr, Guizoni DM, Bonomo C, Nakatani BT, Pai-Silva MD, Carvalho RF, Okoshi K, Okoshi MP. Heart failure-induced skeletal myopathy in spontaneously hypertensive rats. Int J Cardiol. 2013; 167: 698-703.

43. Lima AR, Martinez PF, Okoshi K, Guizoni DM, Zornoff LA, Campos DH, Oliveira SA Jr, Bonomo C, Pai-Silva MD, Okoshi MP. Myostatin and follistatin expression in skeletal muscles of rats with chronic heart failure. Int J Exp Path. 2010; 91: 54-62.
44. Stitt TN, Drujan D, Clarke BA, Panaro F, Timofeyva Y, Kline WO, Gonzalez M, Yancopoulos GD, Glass DJ. The IGF-1/PI3K/Akt pathway prevents expression of muscle atrophy-induced ubiquitin ligases by inhibiting FOXO transcription factors. Mol Cell. 2004; 14: 395-403.

45. Doehner W, Frenneaux M, Anker SD. Metabolic impairment in heart failure: the myocardial and systemic perspective. J Am Coll Cardiol. 2014; 64: 1388-1400.

46. Kandarian SC, Jackman RW. Intracellular signaling during skeletal muscle atrophy. Muscle Nerve. 2006; 33: 155-165.

47. Xu M, Chen X, Chen D, Yu B, Huang Z. FOXO1: a novel insight into its molecular mechanisms in the regulation of skeletal muscle differentiation and fiber type specification. Oncotarget. 2017; 8: 10662-10674. https:// doi.org/10.18632/oncotarget.12891.

48. Cai Y, Dodhia S, Su GH. Dysregulations in the PI3K pathway and targeted therapies for head and neck squamous cell carcinoma. Oncotarget. 2017; 8: 22203-22217. https:// doi.org/10.18632/oncotarget.14729.

49. Furihata T, Kinugawa S, Fukushima A, Takada S, Homma T, Masaki Y, Abe T, Yokota T, Oba K, Okita K, Tsutsui H. Serum myostatin levels are independently associated with skeletal muscle wasting in patients with heart failure. Int $\mathrm{J}$ Cardiol. 2016; 220: 483-487.

50. Damatto RL, Lima AR, Martinez PF, Cezar MD, Okoshi $\mathrm{K}$, Okoshi MP. Myocardial myostatin in spontaneously hypertensive rats with heart failure. Int J Cardiol. 2016; 215: 384-387.

51. Dschietzig TB. Myostatin - from the mighty mouse to cardiovascular disease and cachexia. Clin Chim Acta. 2014; 433: 216-224.

52. Cornelison DD, Wold BJ. Single-cell analysis of regulatory gene expression in quiescent and activated mouse skeletal muscle satellite cells. Dev Biol. 1997; 191: 270-283.

53. Mitchell PO, Pavlath GK. Skeletal muscle atrophy leads to loss and dysfunction of muscle precursor cells. Am J Physiol Cell Physiol. 2004; 287: C1753-C1762.

54. Bacurau AV, Jannig PR, de Moraes WM, Cunha TF, Medeiros A, Barberi L, Coelho MA, Bacurau RF, Ugrinowitsch C, Musaro A, Brum PC. Akt/mTOR pathway contributes to skeletal muscle anti-atrophic effect of aerobic exercise training in heart failure mice. Int J Cardiol. 2016; 214: 137-147.

55. Palus S, Schur R, Akashi YJ, Bockmeyer B, Datta R, Halem H, Dong J, Culler MD, Adams V, Anker SD, Springer J. Ghrelin and its analogues, BIM-28131 and BIM-28125, improve body weight and regulate the expression of MuRF-1 and MAFbx in a rat heart failure model. PLoS One. 2011; 6: e26865.

56. Okoshi MP, Cezar MD, Iyomasa RM, Silva MB, Costa LC, Martinez PF, Campos DH, Damatto RL, Minicucci MF, Cicogna AC, Okoshi K. Effects of early aldosterone antagonism on cardiac remodeling in rats with aortic stenosis-induced pressure overload. Int J Cardiol. 2016; 222: 569-575. 
57. Carvalho RF, Cicogna AC, Campos GE, Assis JM, Padovani CR, Okoshi MP, Pai-Silva MD. Myosin heavy chain expression and atrophy in rat skeletal muscle during transition from cardiac hypertrophy to heart failure. Int $\mathrm{J}$ Exp Path. 2003; 84: 201-206.

58. Pagan LU, Damatto RL, Cezar MD, Lima AR, Bonomo C, Campos DH, Gomes MJ, Martinez PF, Oliveira SA Jr, Gimenes R, Rosa CM, Guizoni DM, Moukbel YC, et al. Long-term low intensity physical exercise attenuates heart failure development in aging spontaneously hypertensive rats. Cell Physiol Biochem. 2015; 36: 61-74.

59. Martinez PF, Bonomo C, Guizoni DM, Junior SA, Damatto RL, Cezar MD, Lima AR, Pagan LU, Seiva FR, Fernandes DC, Laurindo FR, Novelli EL, Matsubara LS, et al. Influence of $\mathrm{N}$-acetylcysteine on oxidative stress in slow-twitch soleus muscle of heart failure rats. Cell Physiol Biochem. 2015; 35: 148-159.

60. Cezar MD, Damatto RL, Martinez PF, Lima AR, Campos DH, Rosa CM, Guizoni DM, Bonomo C, Cicogna AC, Gimenes R, Pagan LU, Okoshi MP, Okoshi K. Aldosterone blockade reduces mortality without changing cardiac remodeling in spontaneously hypertensive rats. Cell Physiol Biochem. 2013; 32: 1275-1287.

61. Okoshi K, Fioretto JR, Okoshi MP, Cicogna AC, Aragon FF, Matsubara LS, Matusbara BB. Food restriction induces in vivo ventricular dysfunction in spontaneously hypertensive rats without impairment of in vitro myocardial contractility. Braz J Med Biol Res. 2004; 37: 607-613.

62. Rosa CM, Gimenes R, Campos DH, Guirado GN, Gimenes C, Fernandes AA, Cicogna AC, Queiroz RM, Falcão-Pires I, Miranda-Silva D, Rodrigues P, Laurindo FR, Fernandes $\mathrm{DC}$, et al. Apocynin influence on oxidative stress and cardiac remodeling of spontaneously hypertensive rats with diabetes mellitus. Cardiovasc Diabetol. 2016; 15: 126.

63. Oliveira Junior SA, Dal Pai-Silva M, Martinez PF, LimaLeopoldo AP, Campos DH, Leopoldo AS, Okoshi MP,
Okoshi K, Padovani CR, Cicogna AC. Diet-induced obesity causes metabolic, endocrine and cardiac alterations in spontaneously hypertensive rats. Med Sci Monit. 2010; 16: BR367-BR373.

64. Martinez PF, Okoshi K, Zornoff LA, Carvalho RF, Oliveira Junior SA, Lima AR, Campos DH, Damatto RL, Padovani CR, Nogueira CR, Pai-Silva MD, Okoshi MP. Chronic heart failure-induced skeletal muscle atrophy, necrosis, and myogenic regulatory factors changes. Med Sci Monit. 2010; 16: 374-383.

65. Yousef H, Conboy MJ, Morgenthaler A, Schlesinger C, Bugaj L, Paliwal P, Greer C, Conboy IM, Schaffer D. Systemic attenuation of the TGF- $\beta$ pathway by a single drug simultaneously rejuvenates hippocampal neurogenesis and myogenesis in the same old mammal. Oncotarget. 2015; 6: 11959-11978. https://doi.org/10.18632/oncotarget.3851.

66. Lima AR, Martinez PF, Damatto RL, Cezar MD, Guizoni DM, Bonomo C, Oliveira SA Jr, Pai-Silva MD, Zornoff LA, Okoshi K, Okoshi MP. Heart failure-induced diaphragm myopathy. Cell Physiol Biochem. 2014; 34: 333-345.

67. Guizoni DM, Oliveira-Junior SA, Noor SL, Pagan LU, Martinez PF, Lima AR, Gomes MJ, Damatto RL, Cezar MD, Bonomo C, Zornoff LA, Okoshi K, Okoshi MP. Effects of late exercise on cardiac remodeling and myocardial calcium handling proteins in rats with moderate and large size myocardial infarction. Int J Cardiol. 2016; 221: 406-412.

68. Cezar MD, Damatto RL, Pagan LU, Lima AR, Martinez PF, Bonomo C, Rosa CM, Campos DH, Cicogna AC, Gomes MJ, Oliveira SA Jr, Blotta DA, Okoshi MP, et al. Early spironolactone treatment attenuates heart failure development by improving myocardial function and reducing fibrosis in spontaneously hypertensive rats. Cell Physiol Biochem. 2015; 36: 1453-1466. 